\title{
IMPLEMENTASI METODE HYBRID SAW-TOPSIS DALAM MULTI ATTRIBUTE DECISION MAKING PEMILIHAN LAPTOP
}

\author{
Wiwien Hadikurniawati $^{1 *}$, Ivannofick AdhaNugraha' ${ }^{1}$, Taufiq Dwi Cahyono ${ }^{2}$ \\ ${ }^{1}$ Teknik Informatika, Universitas Stikubank Semarang \\ ${ }^{2}$ Teknik Elektro, Universitas Semarang \\ email: *wiwien@edu.unisbank.ac.id
}

\begin{abstract}
Various specifications and prices for a laptop make potential buyers confused about choosing it. Information technology with its technological developments has produced a system that can provide alternative decisions for decision-making problems. This study aims to develop a system that can select the best laptop from several alternatives. There are 5 parameters used in determining the priority of alternative laptops. They are hard disk drive, RAM, processor, operating system and price.The alternative of the decision making system also consists of 5 alternatives. The method used in the MultiAttribute Decision Making (MADM) research is a combination of 2 methods. These methods are SAW and TOPSIS methods. The SAW method is used to optimize the parameter weighting process and the specific TOPSIS method to complete the alternative ranking process. This hybrid method can produce a more precise MADM process because it uses two methods, each of which has characteristics in accordance with the process specifications.
\end{abstract}

Keywords: laptop; multi attribute decision making; SAW; TOPSIS

\begin{abstract}
Abstrak: Spesifikasi dan variasi harga yang beragam dari sebuah laptop membuat calon pembeli menjadi kebingungan dan ragu dalam memutuskan jenis atau tipe laptop mana yang akan dibeli. Teknologi informasi beserta dengan perkembangan teknologinya dapat menghasilkan suatu system untuk membantu memberikan alternative keputusan untuk suatu permasalahan pengambilan keputusan. Pengembangan sistem yang dapat memilih laptop yang tepat dari beberapa alternatif yang ditawarkan merupakan tujuan dari penelitian ini. Ada 5 parameter yang digunakan dalam menentukan prioritas alternatif laptop, yaitu hard disk drive, RAM, prosesor, sistem operasi dan harga. Laptop yang ditawarkan sebagai alternatif juga sebanyak 5 jenis. Metode yang digunakan padaMulti Attribute Decision Making (MADM) adalah kombinasi dari 2 metode, yaitu metode SAW dan TOPSIS. Metode SAW digunakan untuk mengoptimalkan proses pembobotan parameter dan metode TOPSIS spesifik untuk menyelesaikan proses perangkingan alternatif. Metode hybrid ini dapat menghasilkan suatu proses MADM yang lebih tepat karena menggunakan dua metode yang masing-masing mempunyai karakteristik sesuai dengan proses yang dilakukannya.
\end{abstract}

Kata kunci: laptop; multi-attribute decision making; SAW; TOPSIS 
DOI: https://doi.org/10.33330/jurteksi.v7i2.907

Available online at http://jurnal.stmikroyal.ac.id/index.php/jurteksi

\section{PENDAHULUAN}

Pengambilan keputusan dapat didefinisikan sebagai proses memilih alternatif yang tepat. Parameter atau variabel yang banyak dan beragam menjadi faktor yang mempersulit terbentuknya keputusan ditambah lagi kemungkinan adanya konflik dari pengambilan keputusan tersebut. Namun sekarang perkembangan ilmu pengetahuan dan teknologi, khususnya untuk ranah penelitian decison making semakin berkembang. Kesulitan dalam pengambilan keputusan (decision making) mendorong para peneliti untuk mengembangkan bidang penelitian Multi-Attribute Decision Making (MADM). MADM dapat memberikan solusi untuk permasalahan pengambilan keputusan yang kompleks[1][2][3].

Masalah pengambilan keputusan dapat terjadi dalam pemilihan suatu barang, dalam hal ini adalah laptop. Berbagaiproduk laptop yang disajikan kepada konsumen meliputi merek, spesifikasi, harga dan fungsional dari laptop. Penawaran laptop yang diberikan semua tokosangat beragam, mulai dari harga, spesifikasi dan lainnya. Keberagaman penawaran laptop tersebut mengakibatkan banyaknya pengguna mengalami kebingungan pada saat memilih laptop yang akandibeli.

Decision making problem dapat diselesaikan dengan teknik SAW. Metode ini kuat pada prosedur pembobotan. Beberapa peneliti menggunakan metode ini pada penelitiannya antara lain. [2]menerapkan metode SAW dalam kasus penerimaan pegawai pada STIMIK Royal. Metode SAW menurut peneliti tersebut lebih fleksibel, dapat menyelesaikan masalah kompleks berdasarkan pengetahuan dan pengalaman manusia. Penelitian yang sama juga dilakukan oleh[3] dengan tujuan untuk menentukan Mitra Jasa Pengiriman Barang Terbaik dengan metode TOPSIS.

\section{Simple Additive Weighting (SAW)}

Metode ini meliputi proses penjumlahan yang berbobot dari rating kinerja pada tiap-tiap alternatif yang memilikiatribut[2][4]. Pada SAW diperlukan proses membuat matrik keputusan yang ternormalisasi menjadi suatu skala. Skala ini dapat dilakukan perbandingan dengan semua tingkat alternatif yang tersediamenggunakan formula 1

$$
r_{i j}=\left\{\begin{array}{l|l|}
\frac{x_{i j}}{\operatorname{Max} x_{i j}} & \text { Jika } \mathrm{j} \text { Benefit } \\
\frac{\operatorname{Min} x_{i j}}{x_{i j}} & \text { Jika } \mathrm{j} \text { Cost }
\end{array}\right.
$$

rij merupakan tingkat kinerja yang ternomalisasi dari alternatif Ai pada atribut $\mathrm{Pi} ; \quad \mathrm{i}=1,2,3, \ldots, \mathrm{m}$ dan $\mathrm{j}=1,2,3, \ldots, \mathrm{m}$. Nilai preferensi alternatif (Vi) ditentukan dengan formula 2

$$
V_{i}=\sum_{j=1}^{n} w_{j} r_{i j}
$$

Vi yang mempunyai nilai lebih tinggi mendasari bahwa alternatif $\mathrm{Ai}$ lebih terpilih, dan untuk kriteria dalammetode SAW terbagi dalam dua kategori yaitu kategori yang bernilai positif atau benefit dan kategori yang bernilai negatif atau cost.

\section{Technique For Order Of Preference By Similarity To Ideal Solution (Topsis)}

Jarak merupakan dasar dari metode TOPSIS. Alternatif yang terseleksi harus mempunyai jarak paling dekat dari solusi ideal positif serta memiliki jarak terpanjang dari solusi 
ideal negatif yang menerapkan euclidean distance untuk menyatakan jarak terdekat dari suatu alternatif terhadap solusi optimal[5][6]. Prosedur dalam pengerjaan metode TOPSIS dengan menormalisasikan matrik keputusan, setiap elemenpada matriks akan dinormalisasikan untuk mendapatkan matriks normalisasi[7]. Proses normalisasi elemen matriks dapat dilakukan dengan rumus 3 .

$r_{i j}=\frac{x_{i j}}{\sqrt{\sum_{t=1}^{m} x^{2} i j}}$

di mana rij merupakan matriks dari hasil normalisasi dari matriks permasalahan dengan $\mathrm{i}=1,2,3, \ldots, \mathrm{m}$ dan $\mathrm{j}=1,2,3, \ldots \mathrm{n}$. $\mathrm{x}_{\mathrm{ij}}$ merupakan matriks awal yang akandinormalisasi. Simbol $i$ menunjukkanbaris dari matriks dan $j$ menunjukkan kolom dari setiap matriks. Setelah menentukan nilai normalisasi maka langkah selanjutnya menghitung normalisasi berbobot menggunakan formula 4

$$
y_{i}=W_{i} * r_{i j}
$$

yij merupakan hasil dari perhitungan $\mathrm{W}$ sebagai bobot dari setiap kriteria dan $r$ merupakan nilai dari setiap kriteria. Dengan didapatkannya nilai normalisasi berbobot maka langkah selanjutnya menentukan ideal positif 5 dan ideal negative sesuai dengan formula 6 .

$$
\begin{aligned}
& \mathrm{A}+=\max (\mathrm{y} 1+, \mathrm{y} 2+, \ldots, \mathrm{yn}+) \\
& \text { A- }=\min (\mathrm{y} 1-, \mathrm{y} 2-, \ldots, \mathrm{yn}-)
\end{aligned}
$$

Proses berikutnya adalah menentukan jarak solusi ideal positif dan menghitung jarak solusi ideal negatif dengan nilai ideal yang telah ditentukan sebagai berikut.

$$
\begin{aligned}
& d_{i}^{*}=\sqrt{\sum_{j=1}^{n} d\left(v_{i j}^{N}, v_{i j}^{N *}\right)^{2}}, i=1,2_{s}, \ldots, m \\
& d_{i}^{-}=\sqrt{\sum_{j=1}^{n} d\left(v_{i j}^{N}, v_{i j}^{N}\right)^{2}}, i=1,2_{s}, \ldots, m \\
& \quad \text { d merupakan nilai dari perhi- }
\end{aligned}
$$
tungan y sebagai nilai ideal negatif dan $\mathrm{x}$ merupakan nilai dari setiap kriteria yang ada. Setelah menentukan nilai jarak ideal positif dan nilai jarak ideal negatif maka selanjutnya adalah menentukan nilai preferensi. $\mathrm{V}$ merupakan nilai preferensi yang didapat dari nilai jarak solusi ideal negatif dibagi nilai jarak negatif ditambah nilai jarak solusi ideal positif. Dari rumus yang telah dipaparkanmaka akan menghasilkan rangking alternatif terbaik[8][9].

\section{METODE}

Metode yang diusulkan pada penelitian ini adalah kombinasi atau gabungan dari metode SAW dan metode TOPSIS. Metode SAW digunakan untuk menentukan pembobotan setiap parameter pengambilan keputusan. Metode TOPSIS sangat cocok untukmenghasilkan prioritas alternatif. Adapun kedua metode tersebut penulis gabungkan menjadi metode yang diusulkan pada penelitian ini. Alur metode yang diusulkan tersebut ditunjukkan dengan diagram blok gambar 1.

Metode yang diusulkan meru-pakan gabungan atau metode hybrid dari SAW dan TOPSIS. Untuk proses pembobotan parameter dan membuat normalisasi matrik keputusan menggunakan metode SAW. Proses selanjutnya menggunakan metode TOPSIS, meliputi perhitungan penentuan solusi idel positif dan solusi 
ideal negatif, menghitung jarak(euclidean distance) antara solusi ideal positif dan negatif serta menentuakan nilai preferensi setiap alternatif.

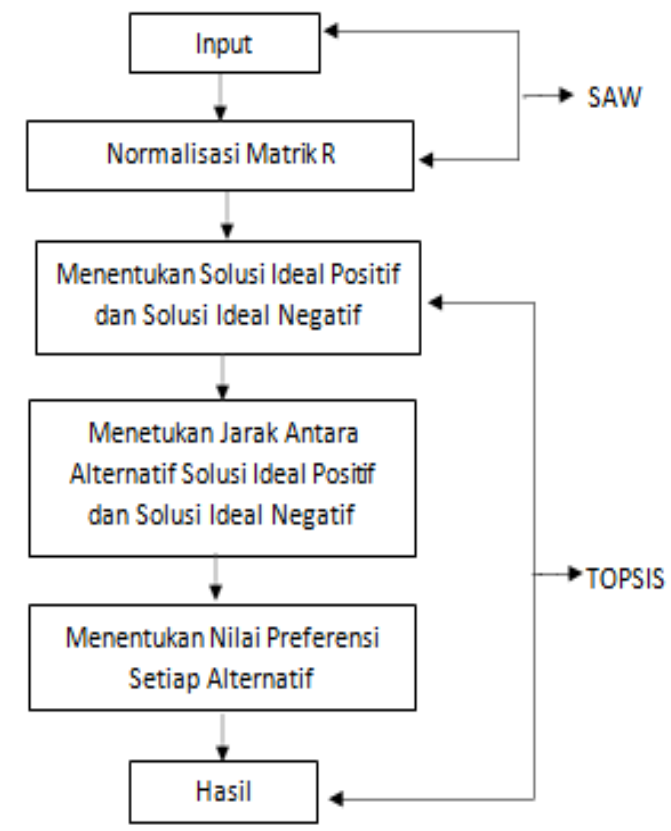

Gambar 1. Metode yang Diusulkan

Nilai preferensi setiap alternatif ini menentukan rangking alternatif. Nilai preferensi suatu alternatif semakin besar maka semakin tinggi rangking alternatifnya[10].

\section{HASIL DAN PEMBAHASAN}

Parameter dari pemilihan laptop telah ditentukan meliputi 5 parameter beserta atributnya seperti Tabel 1 .

Tabel 1. Parameter Pemilihan

\begin{tabular}{lll}
\hline Kode & \multicolumn{1}{c}{ Parameter } & \multicolumn{1}{c}{ Atribut } \\
\hline P1 & RAM & Benefit \\
\hline P2 & Prosesor & Benefit \\
\hline P3 & Harga & Cost \\
\hline P4 & Sistem Operasi & Benefit \\
\hline P5 & HDD & Benefit \\
\hline
\end{tabular}

Setelah menentukan parameter, berikutnya adalah menentukan bobot dari setiap parameter yang diberikan, seperti pada tabel 2 .

Tabel 2. Bobot Parameter

\begin{tabular}{lccccc}
\hline Parameter & P1 & P2 & P3 & P4 & P5 \\
\hline Bobot & $10 \%$ & $25 \%$ & $40 \%$ & $5 \%$ & $20 \%$ \\
\hline
\end{tabular}

Berdasarkan kuesioner tentang parameter pemilihan laptop yang dilakukan atas 100 responden maka dapat dirangkum hasil parameter yang diharapkan dari para calon pembeli laptop, ditunjukkan pada tabel 3.

Matrik keputusan ditentukan dari rating kecocokan alternatif yang dipiliholehcalonpembeli. Matrik keputusan tersebut adalah :

$$
x=\left[\begin{array}{lllll}
10 & 15 & 35 & 25 & 25 \\
35 & 50 & 25 & 25 & 40 \\
20 & 20 & 25 & 20 & 25 \\
30 & 20 & 20 & 35 & 40 \\
20 & 15 & 25 & 25 & 40
\end{array}\right]
$$

Rating kecocokan dalam implementasi sistem ditunjukkan pada Gambar 2.

Proses normalisasi matrik keputusan diperlukan dalam metode SAW. Proses tersebut dihitung menggunakan persamaan (1). Hasil normalisasi $\left(\mathrm{r}_{i j}\right)$ ditunjukkan dalam matrik normalisasi terbobot menggunakan persamaan (4) seperti pada matrik berikut :

$$
x=\left(\begin{array}{ccccc}
0.29 & 0.3 & 0.57 & 0.71 & 0.63 \\
1 & 1 & 0.8 & 0.71 & 1 \\
0.57 & 0.4 & 0.8 & 0.57 & 0.63 \\
0.86 & 0.4 & 1 & 1 & 1 \\
0.57 & 0.3 & 0.8 & 0.71 & 1
\end{array}\right)
$$

Hasil normalisasi terbobot yang didapatkan dari metode SAW kemudian akan dikelompokkan menjadi nilai ideal positif dan nilai ideal negatif dari metode TOPSIS berdasar pada persamaan (5). Kemudian menghitung jarak dari solusi ideal positf dan solusi ideal negatif 
menggunakan persamaan (6) dan (7). Hasil perhitungan tersebut ditunjukkan pada tabel 4.

Tabel 4. Solusi Ideal Positif dan Negatif

\begin{tabular}{ccc}
\hline Alternatif & Di $^{+}$ & Di $^{-}$ \\
\hline A1 & 3.38 & 2.29 \\
\hline A2 & 4.26 & 3.09 \\
\hline A3 & 3.58 & 2.45 \\
\hline A4 & 4.17 & 3.07 \\
\hline A5 & 3.78 & 2.70
\end{tabular}

Langkah terakhir adalah menghitung nilai preferensi yang merupakan nilai prioritas atau rangking dari alternatif. Perhitungan nilai preferensi ditunjukkan pada tabel 5 .

Tabel 5. Preferensi dan Peringkat Alternatif

\begin{tabular}{ccc}
\hline Alternatif & Nilai Preferensi & Peringkat \\
\hline A1 & 0.404 & 4 \\
\hline A2 & 4.200 & 1 \\
\hline A3 & 4.060 & 2 \\
\hline A4 & 0.424 & 3 \\
\hline A5 & 0.380 & 5
\end{tabular}

Semakin tinggi nilai preferensi suatu alternatif maka semakin direkomendasikan alternatif tersebut. Dari perhitungan menggunakan metode hybrid SAW-TOPSIS maka dapat dinyatakan bahwa alternatif A2 yaitu laptop demgan merek ASUS adalah yang terbaik di antara keempat alternatif lainnya.

\section{SIMPULAN}

Metode MADM yang diusulkan dapat membantu pengguna atau calon pembeli dalam memilih laptop yang sesuai dengan spesifikasinya. SAWdigunakan untuk menghitung bobot atribut atau kriteria serta bobot alternatif secara keseluruhan di setiap parameter. MetodeTOPSIS digunakan untuk memperbaiki gap antara performansi alternatif denganhasil aktual serta mencari alternatif terbaik. Dalam penelitian ini parameter terdiri dari 5 parameter yaitu: RAM (P1), Prosesor (P2), Harga (P3), Sistem Operasi (P4), HDD (P5), dan lima alternatif yaitu: Dell (A1), ASUS (A2), Lenovo (A3), ACER (A4) dan Samsung (A5). Kesemuanya ini dianalisis menggunakan metode hybrid SAWTOPSIS. Berdasarkan perhitungan menggunakanmetode campuran SAW dan TOPSIS diperoleh hasil prioritas tertinggi dari alternatif. Alternatif prioritas tertinggi dari 5 parameter adalah laptop merek ASUS.

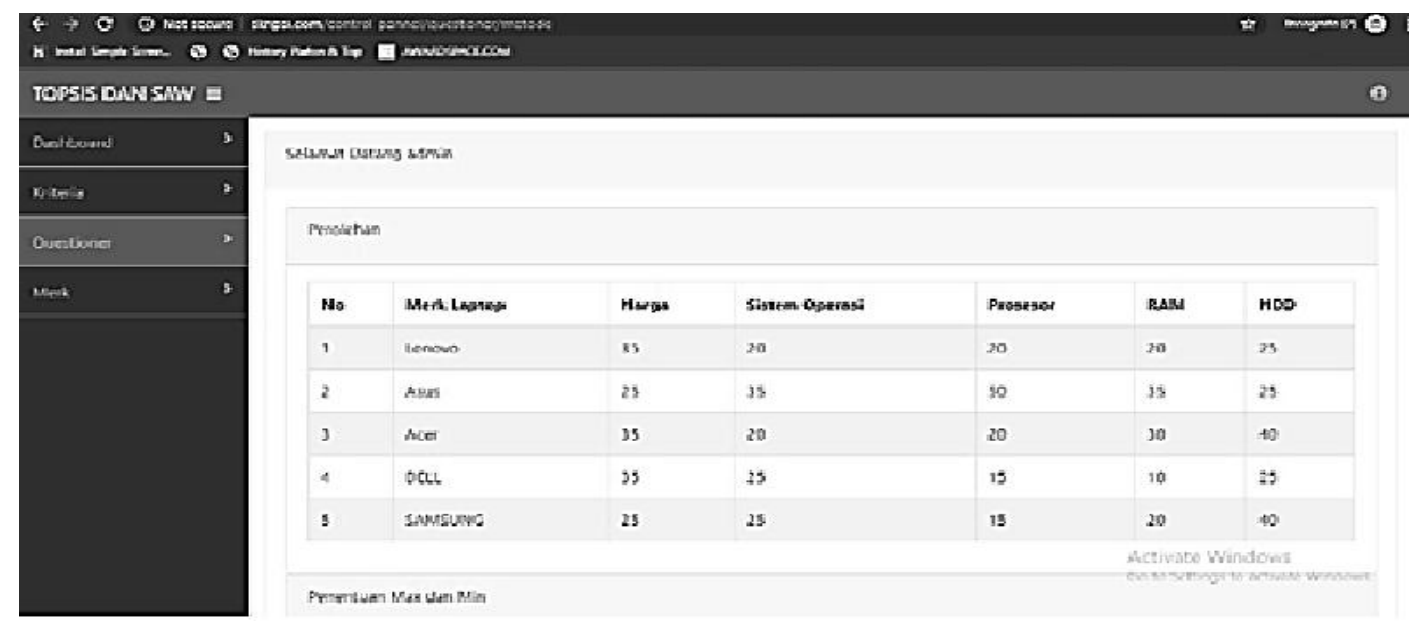

Gambar 2. Rating Kecocokan Alternatif dalam Sistem

Tabel 3. Data Alternatif 
DOI: https://doi.org/10.33330/jurteksi.v7i2.907

Available online at http://jurnal.stmikroyal.ac.id/index.php/jurteksi

\begin{tabular}{llcllll}
\hline No & Merk & RAM & $\begin{array}{l}\text { Proces- } \\
\text { sor }\end{array}$ & Harga & $\begin{array}{l}\text { Siste- } \\
\text { mOperasi }\end{array}$ & HDD \\
\hline 1. & Dell & 2GB & Core i3 & 5Jt & Windows 8 & 500GB \\
\hline 2. & Asus & 10GB & Core i7 & 5Jt s/d 8Jt & Windows 8 & $1 \mathrm{~TB}$ \\
\hline 3. & Lenovo & 4GB & Core i5 & 5Jt s/d 8Jt & Windows 7 & 500GB \\
\hline 4. & Acer & 8GB & Core i5 & 7Jt s/d 9Jt & Windows 10 & $1 \mathrm{~TB}$ \\
\hline 5. & Samsung & 4GB & Core i3 & 5Jt s/d 8Jt & Windows 8 & $1 \mathrm{~TB}$ \\
\hline
\end{tabular}

\section{DAFTAR PUSTAKA}

[1] W. Hadikurniawati and R. Wardoyo, "A hybrid multiattribute decision making for electrician selection based on ahp, saw and topsis," J. Theor. Appl. Inf. Technol., vol. 77, no. 1, pp. 136-142, 2015.

[2] A. Afrisawati, "Sistem Pendukung Keputusan Penerimaan Pegawai di STMIK Royal Menggunakan Metode Simple Additive Weighting," JURTEKSI, 2017, doi: 10.33330/jurteksi.v4i1.23.

[3] Risnawati and N. Manurung, "Sistem Pendukung Keputusan Dalam Penentuan Mitra Jasa Pengiriman Barang Terbaik Di Kota Kisaran Menggunakan Metode Topsis," vol. V, no. 2, pp. 133-138, 2019.

[4] H. Hermanto and N. Izzah, "Sistem Pendukung Keputusan Pemilihan Motor Dengan Metode Simple Additive Weighting (SAW)," Mat. DAN PEMBELAJARAN, 2018, doi: 10.33477/mp.v6i2.669.

[5] W. Hadikurniawati, E. Winarno, D. B. Santoso, and Purwatiningtyas, "A Mixed Method using AHP-TOPSIS for Dryland Agriculture Crops Selection Problem," 2019, doi: 10.1109/ICICoS48119.2019.89824
15.

[6] B. A. Benning, I. F. Astuti, and D. M. Khairina, "Sistem Pendukung Keputusan Pembelian Perangkat Komputer Dengan Metode Topsis (Studi Kasus: Cv. Triad)," Inform. Mulawarman J. Ilm. Ilmu Komput., vol. 10, no. 2, p. 1, 2015, doi: 10.30872/jim.v10i2.183.

[7] N. D. Palasara and T. Baidawi, "Penerapan Metode Topsis Pada Peningkatan Kinerja Karyawan," J. Inform., vol. 5, no. 2, pp. 287294, 2018, [8] T. Kristina, "Sistem Pendukung Keputusan Dengan Menggunakan Metode TOPSIS Untuk Pemilihan Lokasi Pendirian Grosir Pulsa," Paradigma, vol. 20, no. 1, pp. 812, 2018, [Online]. Available: https://ejournal.bsi.ac.id/ejurnal/in dex.php/paradigma/article/view/29 08 .

[9] "METODE FUZZY TOPSIS MADM SEBAGAI ALTERNATIF PENGAMBILAN KEPUTUSAN MENENTUKAN PENERIMA BEASISWA PPA BERBASIS WEB," Unnes $J$. Math., 2016,

[10] Sunarti, J. Sundari, S. Anggraeni, F. B. Siahaan, and Jimmi, "Comparison topsis and saw method in the selection of tourism destination in Indonesia," 2018, 